\title{
EFEITO DO TRATAMENTO QUÍMICO SOBRE A CONSERVAÇÃO DE SEMENTES DE MILHO DURANTE O ARMAZENAMENTO ${ }^{1}$
}

\author{
SIMONE APARECIDA FESSEL ${ }^{2}$, ELISABETH APARECIDA FURTADO DE MENDONÇA ${ }^{3}$, \\ ROBERTO VENCESLAU DE CARVALHO ${ }^{3}$, ROBERVAL DAITON VIEIRA ${ }^{4}$
}

\begin{abstract}
RESUMO - O objetivo do trabalho foi estudar o efeito de combinações de inseticidas e de fungicidas sobre a conservação de sementes de milho durante o armazenamento. Os tratamentos aplicados e respectivas doses, para $1000 \mathrm{~kg}$ de sementes, foram os seguintes: 1) testemunha; 2) anilina (936mL); 3) anilina $(936 \mathrm{~mL})+$ Thiabendazole $(120 \mathrm{~g})+$ Dicarboximida $(187,5 \mathrm{~g})+$ Pirimifos- methyl $(6,25 \mathrm{~mL})+$ Deltamethrin $(0,75 \mathrm{~mL}) ; 4)$ anilina $(936 \mathrm{~mL})+$ Thiabendazole $(240 \mathrm{~g})+$ Dicarboximida $(375,0 \mathrm{~g})+$ Pirimifos- methyl $(12,50 \mathrm{~mL})+$ Deltamethrin $(1,50 \mathrm{~mL}) ; 5)$ anilina $(936 \mathrm{~mL})+$ Thiabendazole (480g) + Dicarboximida (750,0g) + Pirimifos- methyl (25,00mL) + Deltamethrin $(3,00 \mathrm{~mL}) ; 6)$ anilina $(936 \mathrm{~mL})+$ Thiabendazole $(960 \mathrm{~g})+$ Dicarboximida $(1500,0 \mathrm{~g})+$ Pirimifosmethyl $(50,00 \mathrm{~mL})+$ Deltamethrin $(6,00 \mathrm{~mL})$. As sementes foram analisadas quanto ao teor de água, germinação e vigor (testes de envelhecimento acelerado e de frio com solo) aos 0, 6, 9 e 12 meses de armazenamento. Os dados obtidos permitiram concluir que os tratamentos químicos aplicados tendem, com o aumento das dosagens, a gerar efeitos latentes, desfavoráveis ao desempenho das sementes, intensificados com o prolongamento do período de armazenamento.

Termos para indexação: Zea mays, qualidade fisiológica.
\end{abstract}

\section{EFFECT OF CHEMICAL TREATMENT ON CORN SEEDS CONSERVATION DURING STORAGE}

\begin{abstract}
The purpose of this research was to study the effect of varying dosages of insecticide and fungicide on the conservation of stored seeds. The products and dosages for each $1000 \mathrm{Kg}$ of seeds were: 1) control; 2) aniline $(936 \mathrm{~mL})$; 3) aniline $(936 \mathrm{~mL})+$ Thiabendazole $(120 \mathrm{~g})+$ Dicarboximida (187.5g) + Pirimifos- methyl (6.25mL) + Deltamethrin (0.75mL); 4) aniline (936mL) + Thiabendazole (240g) + Dicarboximida (375.0g) + Pirimifos- methyl (12.50mL) + Deltamethrin $(1.50 \mathrm{~mL})$; 5) aniline $(936 \mathrm{~mL})+$ Thiabendazole $(480 \mathrm{~g})+$ Dicarboximida $(750.0 \mathrm{~g})+$ Pirimifosmethyl $(25,00 \mathrm{~mL})+$ Deltamethrin $(3.00 \mathrm{~mL}) ; 6)$ aniline $(936 \mathrm{~mL})+$ Thiabendazole $(960 \mathrm{~g})+$ Dicarboximida $(1500,0 \mathrm{~g})+$ Pirimifos- methyl $(50.00 \mathrm{~mL})+$ Deltamethrin $(6.00 \mathrm{~mL})$. The seeds were analyzed for moisture content, germination and vigor (accelerated aging and cold tests) at 0 , 6, 9 and 12 months of storage. From the information obtained we can conclude that the chemical treatment applied tended, with the increase of dosages, to produce latent effects unfavorable to the seed performance, that were intensified with the prolongation of the storage period..
\end{abstract}

Index terms: Zea mays, physiological quality.

\footnotetext{
${ }^{1}$ Aceito para publicação em 18.02.2003.

2 Pós-Graduandas em Produção e Tecnologia de Sementes na FCAV/UNESP, 14884-900, Jaboticabal,SP.

${ }^{3}$ Melhorista e fitopatologista da Empresa Dow AgroSciences; Jardinópolis, SP.

${ }^{4}$ Prof. Titular do Depto. de Produção Vegetal, FCAV/UNESP; bolsista CNPq; e-mail: rdvieira@fcav.unesp.br
}

\section{INTRODUÇÃO}

A preservação da qualidade das sementes de cereais é influenciada pela presença de insetos que, paulatinamente, têm se adaptado para desenvolver populações em ambientes de armazenamento. Além de atuarem como consumidores, os insetos afetam negativamente o valor intrínseco das sementes, principalmente, ao propiciar a ação de microrganismos indesejáveis. 
As sementes de milho, nas condições brasileiras, são rotineiramente tratadas, considerando-se que os produtos aplicados nas sementes, eficientes na preservação de perdas, sejam de menor impacto ambiental do que os utilizados em campo.

A preservação da qualidade das sementes, durante o armazenamento, colabora para o efetivo aproveitamento dos investimentos despendidos na produção (Carvalho, 1992). Pereira (1986) cita que, entre as medidas preventivas utilizadas na proteção das sementes de milho durante o armazenamento, o tratamento químico tornou-se um procedimento rotineiro dos processos de produção. Segundo esse mesmo autor, embora a principal finalidade do uso de fungicidas em sementes seja a proteção contra microrganismos de solo, o tratamento pode controlar fungos relacionados com a deterioração durante o armazenamento.

Faria (1990) revelou que o tratamento das sementes de milho, com o fungicida Dicarboximida e o inseticida Deltamethrin, foram eficientes na preservação da qualidade das sementes de milho, durante 12 meses, em armazenamento desprovido de controles de temperatura e de umidade relativa.

Contudo, há necessidade de constante busca de novas opções para o tratamento químico. Nesse sentido, o presente trabalho objetivou estudar os efeitos de combinações de inseticidas e de fungicidas sobre a conservação de sementes de milho durante o armazenamento.

\section{MATERIAL E MÉTODOS}

Foram utilizadas sementes de milho, do cultivar D657, retidas durante a classificação na peneira de crivos oblongos com largura de 15/64 de polegada. Previamente ao armazenamento, foram aplicados os tratamentos indicados na Tabela 1.

As sementes, armazenadas em condições laboratoriais $\left( \pm 27^{\circ} \mathrm{C}\right.$ e $\left.70 \% \mathrm{UR}\right)$, foram avaliadas aos $0,6,9$ e 12 meses através dos seguintes testes: a) teor de água das sementes: foi determinado em duas repetições de 25 sementes pelo método de estufa a $105 \pm 3^{\circ} \mathrm{C}$, por 72 horas (ISTA, 1993). b) teste de germinação: realizado com quatro repetições de 50 sementes, instaladas em rolo de papel toalha umedecido com água na proporção de 3:1 (peso da água: peso do papel seco), foi conduzido a $25^{\circ} \mathrm{C}$ e avaliado de acordo com as Regras para Análise de Sementes (Brasil, 1992). c) envelhecimento acelerado: empregando quatro repetições, constou da distribuição das sementes em camada única, protegida do contato com água líquida, sobre tela instalada no interior de caixa plástica que continha $40 \mathrm{~mL}$ de água deionizada; depois da permanência a $45^{\circ} \mathrm{C} / 72 \mathrm{~h}$ (Hampton \& Tekrony, 1995 e Fessel et al., 2000), foram determinados o teor de água e a germinação das sementes. d) frio com solo: conduzido com quatro repetições de 50 sementes instaladas em mistura de areia e terra (2:1) umedecida (70\% da capacidade de retenção) e distribuídas no interior de caixas plásticas que, tampadas, foram colocadas em câmara $\left(10^{\circ} \mathrm{C} / 7\right.$ dias); vencido o período, as caixas foram destampadas e mantidas a $25-30^{\circ} \mathrm{C}$ para, após cinco dias, ser estimada a taxa (\%) de plântulas emersas (AOSA, 1983).

Empregando delineamento inteiramente casualizado, as médias foram comparadas pelo teste de Tukey a 5\% de probabilidade.

\section{RESULTADOS E DISCUSSÃO}

Os dados do teor de água (Tabela 2), excetuando-se a superioridade verificada na testemunha em relação aos tratamentos 3, 4 e 5 no início do armazenamento, indicaram ausência de efeitos nos demais casos. Além desse aspecto, os valores absolutos encontrados, invariavelmente inferiores a $13 \%$, sugeriram a existência permanente de teores de água adequados à conservação das sementes de milho. Puzzi (2000) observou que o conteúdo máximo de água das sementes de

TABELA 1. Relação de tratamentos e doses dos respectivos produtos químicos.

\begin{tabular}{lccccc}
\hline \multirow{2}{*}{ Tratamentos } & \multicolumn{5}{c}{ Produtos (i.a./1000Kg de sementes) } \\
\cline { 2 - 6 } & $\begin{array}{c}\text { Anilina } \\
(\mathrm{mL})\end{array}$ & $\begin{array}{c}\text { Thiabendazole } \\
(\mathrm{g})\end{array}$ & $\begin{array}{c}\text { Dicarboximida } \\
(\mathrm{g})\end{array}$ & $\begin{array}{c}\text { Pirimifos- methyl } \\
(\mathrm{mL})\end{array}$ & $\begin{array}{c}\text { Deltamethrin } \\
(\mathrm{mL})\end{array}$ \\
\hline 1 (Testemunha) & - & - & - & - & - \\
2 & 936 & - & - & - & - \\
3 & 936 & 120 & 187,5 & 6,25 & 0,75 \\
4 & 936 & 240 & 375,0 & 12,50 & 1,50 \\
5 & 936 & 480 & 750,0 & 25,00 & 3,00 \\
6 & 936 & 960 & 1500,0 & 50,00 & 6,00 \\
\hline
\end{tabular}


TABELA 2. Teor de água: Dados (\%) obtidos em sementes de milho submetidas a diferentes tratamentos químicos e períodos de armazenamento.

\begin{tabular}{lcccc}
\hline \multirow{2}{*}{ Tratamentos } & \multicolumn{4}{c}{ Período de armazenamento (meses) } \\
\cline { 2 - 5 } & 0 & 6 & 9 & 12 \\
\hline 1 (Testemunha) & $10,20 \mathrm{a}$ & $9,39 \mathrm{a}$ & $10,62 \mathrm{a}$ & $11,36 \mathrm{a}$ \\
2 & $9,97 \mathrm{ab}$ & $9,74 \mathrm{a}$ & $10,67 \mathrm{a}$ & $11,52 \mathrm{a}$ \\
3 & $9,56 \mathrm{~b}$ & $9,58 \mathrm{a}$ & $10,74 \mathrm{a}$ & $11,13 \mathrm{a}$ \\
4 & $9,64 \mathrm{~b}$ & $9,45 \mathrm{a}$ & $10,74 \mathrm{a}$ & $11,75 \mathrm{a}$ \\
5 & $9,73 \mathrm{~b}$ & $9,67 \mathrm{a}$ & $11,11 \mathrm{a}$ & $11,61 \mathrm{a}$ \\
6 & $10,00 \mathrm{ab}$ & $9,46 \mathrm{a}$ & $10,80 \mathrm{a}$ & $11,30 \mathrm{a}$ \\
\hline CV (\%) & 1,17 & 2,70 & 2,43 & 1,80 \\
\hline
\end{tabular}

Médias seguidas pela mesma letra na coluna não diferem entre si pelo teste de Tukey a $5 \%$ de probabilidade.

milho, visando obter segurança no armazenamento, sem ponderáveis alterações no peso e nos componentes químicos, é de 13\%; esse valor é o máximo permitido pela Legislação Federal para conservação de sementes de milho (Brasil, 1989).

A maior variação observada entre os teores de água (Tabela 3), após o envelhecimento acelerado, foi de 2,5\% aos 6 meses de armazenamento. Essa diferença, situada na faixa tolerada (3 - 4\%) por Marcos-Filho (1999), atribuiu confiabilidade aos dados fornecidos pelo teste para as comparações entre o desempenho dos tratamentos.

TABELA 3. Teor de água após o envelhecimento acelerado: Dados (\%) obtidos em sementes de milho submetidas a diferentes tratamentos químicos e períodos de armazenamento.

\begin{tabular}{lcllll}
\hline \multirow{2}{*}{ Tratamentos } & \multicolumn{5}{c}{ Período de armazenamento (meses) } \\
\cline { 2 - 5 } & \multicolumn{1}{c}{0} & \multicolumn{1}{c}{6} & \multicolumn{1}{c}{9} & 12 \\
\hline \multirow{2}{*}{ (Testemunha) } & $24,54 \mathrm{a}$ & 22,66 & $\mathrm{bc}$ & $23,60 \mathrm{~b}$ & $24,06 \mathrm{~b}$ \\
2 & $25,21 \mathrm{a}$ & $23,70 \mathrm{abc}$ & $24,20 \mathrm{ab}$ & $23,96 \mathrm{~b}$ \\
3 & $24,57 \mathrm{a}$ & 22,49 & $\mathrm{c}$ & $24,85 \mathrm{a}$ & $25,22 \mathrm{a}$ \\
4 & $25,48 \mathrm{a}$ & $24,17 \mathrm{ab}$ & $24,84 \mathrm{a}$ & $24,99 \mathrm{ab}$ \\
5 & $26,22 \mathrm{a}$ & $24,99 \mathrm{a}$ & $24,70 \mathrm{a}$ & $25,67 \mathrm{a}$ \\
6 & $25,65 \mathrm{a}$ & $23,46 \mathrm{abc}$ & $24,00 \mathrm{ab}$ & $24,64 \mathrm{ab}$ \\
\hline $\mathrm{CV}(\%)$ & 2,01 & 1,69 & 1,11 & 1,07 \\
\hline
\end{tabular}

Médias seguidas pela mesma letra na coluna não diferem entre si pelo teste de Tukey a $5 \%$ de probabilidade.

Os dados obtidos no teste de germinação (Tabela 4) permitem observar que os tratamentos 2, 3, 4 e 5 apresentaram comportamento similar ao da testemunha em todos os períodos. O tratamento 6, por outro lado, foi significativamente
TABELA 4. Teste de germinação: Dados (\%) obtidos em sementes de milho submetidas a diferentes tratamentos químicos e períodos de armazenamento.

\begin{tabular}{|c|c|c|c|c|}
\hline \multirow{2}{*}{ Tratamentos } & \multicolumn{4}{|c|}{ Período de armazenamento (meses) } \\
\hline & 0 & 6 & 9 & 12 \\
\hline 1 (Testemunha) & $99 a$ & $95 a b$ & $95 a$ & $94 a$ \\
\hline 2 & $97 a$ & $96 a b$ & $94 a$ & $97 a$ \\
\hline 3 & $97 a$ & $98 a$ & $94 a$ & $97 a$ \\
\hline 4 & $99 a$ & $95 a b$ & $90 \mathrm{ab}$ & $94 a$ \\
\hline 5 & $96 a b$ & 88 bc & $89 a b$ & $92 a b$ \\
\hline 6 & $93 \mathrm{~b}$ & $82 \mathrm{c}$ & $85 \mathrm{~b}$ & $87 \mathrm{~b}$ \\
\hline CV (\%) & 1,82 & 18,28 & 2,89 & 2,73 \\
\hline
\end{tabular}

Médias seguidas pela mesma letra na coluna não diferem entre si pelo teste de Tukey a $5 \%$ de probabilidade.

inferior à testemunha em todos os períodos de avaliação; esse comportamento diferenciado associou-se com a maior concentração de ingredientes ativos presente entre os tratamentos. Oliveira \& Cruz (1986) observaram que o tratamento de sementes de milho, com inseticidas, provocou efeito negativo sobre a germinação das sementes e este efeito intensificou-se com o prolongamento do período de armazenamento.

Com relação ao desempenho das sementes no teste de frio (Tabela 5), observa-se que no início do arma-zenamento os tratamentos apresentaram desempenho equivalente. A partir de seis meses de armazenamento, contudo, os tratamentos passaram a diferenciar-se e, ao final do período, os tratamentos 5 e 6, com maiores dosagens de ingredientes ativos, foram inferiores aos demais.

TABELA 5. Teste de frio: Dados (\%) obtidos em sementes de milho submetidas a diferentes tratamentos químicos e períodos de armazenamento.

\begin{tabular}{|c|c|c|c|c|}
\hline \multirow{2}{*}{ Tratamentos } & \multicolumn{4}{|c|}{ Período de armazenamento (meses) } \\
\hline & 0 & 6 & 9 & 12 \\
\hline 1 (Testemunha) & $83 a$ & $80 \mathrm{~b}$ & $75 \mathrm{~b}$ & $77 \mathrm{~b}$ \\
\hline 2 & $89 a$ & $79 \mathrm{~b}$ & $74 \mathrm{~b}$ & $83 a b$ \\
\hline 3 & $91 \mathrm{a}$ & $88 a$ & $88 \mathrm{a}$ & $88 \mathrm{a}$ \\
\hline 4 & $89 a$ & $91 \mathrm{a}$ & $91 \mathrm{a}$ & $80 \mathrm{ab}$ \\
\hline 5 & $89 a$ & 81 bc & $77 \mathrm{~b}$ & $64 \mathrm{c}$ \\
\hline 6 & $87 a$ & $62 d$ & $73 \mathrm{~b}$ & 45 \\
\hline CV (\%) & 4,58 & 5,00 & 4,17 & 5,67 \\
\hline
\end{tabular}

Médias seguidas pela mesma letra na coluna não diferem entre si pelo teste de Tukey a $5 \%$ de probabilidade. 
Os dados obtidos no teste de envelhecimento acelerado estão apresentados na Tabela 6. No início do armazenamento, a testemunha mostrou-se inferior a todos os demais tratamentos contrariando as informações fornecidas pelos demais testes; contudo, deixando de ocorrer nos períodos subseqüentes, o fato foi atribuído a desvio de natureza experimental e, dessa maneira, desconsiderado. Verifica-se que, após 12 meses de armazenamento, os tratamentos 5 e 6, com maiores dosagens de produtos químicos, provocaram inferioridades significativas similares às verificadas no teste de frio.

TABELA 6. Teste de envelhecimento acelerado: Dados (\%) obtidos em sementes de milho submetidas a diferentes tratamentos químicos e períodos de armazenamento.

\begin{tabular}{|c|c|c|c|c|}
\hline \multirow{2}{*}{ Tratamentos } & \multicolumn{4}{|c|}{ Período de armazenamento (meses) } \\
\hline & 0 & 6 & 9 & 12 \\
\hline 1 (Testemunha) & 59 & $75 a$ & $35 a$ & $18 \mathrm{a}$ \\
\hline 2 & $78 \quad \mathrm{c}$ & $74 \mathrm{ab}$ & $17 \mathrm{~b}$ & $21 \mathrm{a}$ \\
\hline 3 & $93 a$ & $77 \mathrm{a}$ & $17 \mathrm{~b}$ & $18 \mathrm{a}$ \\
\hline 4 & $96 a$ & $82 a$ & $11 \mathrm{bc}$ & $18 \mathrm{a}$ \\
\hline 5 & $90 \mathrm{ab}$ & $61 \mathrm{~b}$ & 11 bc & $6 \mathrm{~b}$ \\
\hline 6 & 83 bc & $45 \mathrm{C}$ & $8 \mathrm{c}$ & $6 \mathrm{~b}$ \\
\hline CV (\%) & 4,76 & 7,92 & 19,10 & 22,78 \\
\hline
\end{tabular}

Médias seguidas pela mesma letra na coluna não diferem entre si pelo teste de Tukey a $5 \%$ de probabilidade.

De um modo geral, a redução na viabilidade e no vigor das sementes, condicionada pelos produtos químicos empregados, intensificou-se com o aumento das dosagens e com o prolongamento do período de armazenamento. Dessa forma, a aplicação de produtos combinados, com ingredientes ativos e modo de ação distintos, deve contar com estudos capazes de estimar os efeitos fisiológicos, imediatos e latentes, provocados pelo tratamento.

\section{CONCLUSÕES}

- Os tratamentos químicos aplicados tendem, com o aumento das dosagens, a gerar efeitos latentes, desfavoráveis ao desempenho das sementes, intensificados com o prolongamento do período de armazenamento.

\section{REFERÊNCIAS}

ASSOCIATION OF OFFICIAL SEED ANALYSTS. Seed vigor testing handbook. East Lasing, 1983. 93p. (Contribution, 32).

BRASIL. Ministério da Agricultura e da Reforma Agrária. Regras para análise de sementes. Brasília: SNAD/DNPV/ CLAV, 1992. 365p.

BRASIL. Ministério da Agricultura. Comissão Nacional de Sementes e Mudas. Legislação Federal de Sementes e Mudas. Brasília, 1989. 318p.

CARVALHO, M.L.M. Refrigeração e qualidade de sementes de milho armazenadas em pilhas com diferentes embalagens. 1992. 96f. Tese (Doutorado) - Escola Superior de Agricultura Luiz de Queiroz, Piracicaba.

FARIA, L.A.L. Efeitos de embalagens e do tratamento químico na qualidade de sementes de algodão, feijão, milho e soja armazenadas sob condições ambiente. 1990. 122f. Dissertação (Mestrado) - Escola Superior de Agricultura de Lavras, Lavras.

FESSEL, S.A.; RODRIGUES, T.J.D.; FAGIOLI, M.; VIEIRA, R.D. Temperatura e período no teste de envelhecimento acelerado em sementes de milho. Revista Brasileira de Sementes, Brasília, v.22, n.2, p.163-170, 2000.

HAMPTON, J.G.; TEKRONY, D.M. Handbook of vigour test methods. 3.ed., Zurich: ISTA, 1995. 117p.

INTERNATIONAL SEED TESTING ASSOCIATION - ISTA. International Rules for Seed Testing. Seed Science and Technology, Zürich, v.21, (supplement), 1993. 288p.

MARCOS-FILHO, J. Teste de envelhecimento acelerado. In: KRZYZANOWSKI, F.C., VIEIRA, R.D., FRANÇA NETO, J. B. (Ed.) Vigor de sementes: conceitos e testes. Londrina: ABRATES. 1999. p.3.1-3.24.

OLIVEIRA, L.J.; CRUZ, I. Efeito de diferentes inseticidas e dosagens na germinação de sementes de milho (Zea mays L.). Pesquisa Agropecuária Brasileira, Brasília, v.21, n.6, p.578-585, 1986.

PEREIRA, O.A.P. Tratamento de sementes de milho. In: SIMPÓSIO BRASILEIRO DE PATOLOGIA DE SEMENTES, 2., Campinas, 1986. Resumos... Campinas: Fundação Cargill, 1986. p.145-148.

PUZZI, D. Abastecimento e armazenagem de grãos. Campinas: Instituto Campineiro de Ensino Agrícola, 2000. 666p.

SEED SCIENCE AND TECHNOLOGY, Zürich, v.21, 1993. 288p. Supplement. 